Connotas. Revista de crítica y teoría literarias 


\begin{tabular}{|ll|}
\hline PQ6001 & Connotas. Revista de crítica y teoría literarias / \\
Director Fortino Corral Rodríguez.-Hermosillo, Sonora: \\
unIson. Departamento de Letras y Lingüística. \\
C2011. \\
V-: $23 \mathrm{~cm}$. \\
Semianual \\
Año VII, No. $12(2011)$ \\
ISSN: 1870-6630 \\
Incluye bibliografía. \\
1. Literatura española - Historia y crítica-Publicaciones \\
periódicas. 2. Literatura hispanoamericana - Publicaciones \\
periódicas. I. Corral Rodríguez, Fortino, dir.
\end{tabular}

CONNOTAS. REVISTA DE CRÍTICA Y TEORÍA LITERARIAS. Año VII, núm. 12, enero junio 2011, es una publicación semestral editada por la Universidad de Sonora, a través de la División de Humanidades y Bellas Artes, en el Departamento de Letras y Lingüística. Blvd. Luis Encinas y Blvd. Rosales s/n, Col. Centro, C.P. 83000, Hermosillo Sonora; Tel. (662) 2592 136, (662) 2592 157, <www.uson.mx>, <http://www.connotas.uson.mx, connotas@capomo.uson.mx>. Editor responsable: Rosario Fortino Corral Rodríguez. Reservas de Derechos al Uso Exclusivo núm. 04-2006-020714184900-102. ISSN: 1870 6630; ambos otorgados por el Instituto Nacional del Derecho de Autor. Licitud de Título núm. 13434 y de Contenido núm. 11007, otorgados por la Comisión Calificadora de Publicaciones y Revistas Ilustradas de la Secretaría de Gobernación. Impresa en Impresos RM S.A. de C.V., Privada Miguel Alemán no. 17, col. San Benito, Hermosillo, Sonora, México. Tel. 2 100212, e-mail impresosrm@gmail.com. Este número se terminó de imprimir el 5 de octubre de 2011 con un tiraje de 300 ejemplares. Las opiniones expresadas por los autores no necesariamente reflejan la postura del editor de la publicación.

Se autoriza la reproducción total o parcial de los contenidos de la presente publicación, siempre y cuando se acredite adecuadamente el origen de los mismos.

Este número se publicó con apoyo del Programa Integral de Fortalecimiento Institucional

Datos de contacto para la publicación: División de Humanidades y Bellas Artes, Departamento de Letras y Lingüística; Apartado Postal 793, Col. Centro, C.P. 83000, Hermosillo, Sonora, México. Tels.: (662) 259-21-87, Tel-fax 212-55-29. Correo electrónico: connotas@capomo.uson.mx Página web: http://www.connotas.uson.mx 


\section{Connotas. Revista de crítica y teoría literarias}

Año VII / Núm. 12 / Enero-junio 2011

COMPILAdOR DE ESTE NÚMERO

César Avilés Icedo

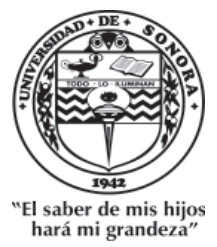

UNIVERSIDAD DE SONORA 


\section{UNIVERSIDAD DE SONORA}

RECTOR

Heriberto Grijalva Monteverde

VicerReCTORA

Arminda Guadalupe García de León Peñúñuri

Secretario General Académico

Enrique Fernando Velázquez Contreras

División de Humanidades y Bellas Artes

María Rita Plancarte Martínez

DePARTAMENTO DE LETRAS Y LINGÜÍSTICA

Martha Martínez Figueroa

COMItÉ EDITORIAL INTERNO

César Avilés Icedo

Rosa María Burrola Encinas

Fortino Corral Rodríguez

Leticia Martínez Figueroa

Jesús Abad Navarro Gálvez

Gabriel Osuna Osuna

María Rita Plancarte Martínez

DiRECTOR

Fortino Corral Rodríguez

Giuseppe Bellini

Universidad de Milán

Luis Beltrán Almería

Universidad de Zaragoza

Helena Beristáin

Universidad Nacional Autónoma de México

Raúl Bueno-Chávez

Dartmouth College

Evodio Escalante

Universidad Autónoma Metropolitana

Beatriz González-Stephan

Rice University

Aníbal González Pérez

Yale University

Aurelio González Pérez

El Colegio de México

Yvette Jiménez de Báez

El Colegio de México

Nelson Osorio Tejeda

Universidad de Santiago de Chile

\section{CONSEJO INTERNACIONAL}

Carlos Pacheco

Universidad Simón Bolivar

Rafael Olea Franco

El Colegio de México

Joan Oleza Simó

Universidad de Valencia

Julio Ortega

Brown University

Luz Aurora Pimentel

Universidad Nacional Autónoma de México

Susana Reisz

The City University of New York

José Carlos Rovira

Universidad de Alicante

Charles Tatum

The University of Arizona

Jorge Urrutia

Universidad Carlos III de Madrid

Emil Volek

Arizona State University 


\section{Índice}

\section{Artículos}

La ciudad fronteriza de Luis Humberto Crosthwaite en Estrella de la calle sexta e Instrucciones para cruzar la frontera

Martín Torres SaUchetT . . . . . . . . . . . . . . 9

Artífices y simuladores: el influjo de los medios masivos y la cultura popular en la literatura latinoamericana del siglo XX Amalia Franco Castaño . . . . . . . . . . . . . . 27

“Teoría del túnel”: El pre-texto de Rayuela Margarita Díaz de León Ibarra . . . . . . . . . . . . . . 45

Metaficción hispanoamericana y crisis de la representación literaria del sujeto

Jesús Eduardo Oliva Abarca . . . . . . . . . . . . . 61

Los refranes y los poemínimos: análisis de una relación intertextual

IsAbelle Pouzet . . . . . . . . . . . . . . . . . . . . . . . . 79

\section{Notas}

La ciudad como categoría estética e ideológica en Cartas de relación de Hernán Cortés y Grandeza mexicana de Bernardo de Balbuena Jesús Abad Navarro Gálvezz . . . . . . . . . . . . . . . . . 99 
Hacia una hermenéutica estridentista: de la crítica romántica a la crítica de vanguardia

Alberto Rodríguez González . . . . . . . . . . . . . . . . 111

Casas de encantamiento y El espía del aire, de Ignacio Solares: la reflexión de la escritura

Alejandra Sánchez Aguilar . . . . . . . . . . . . . . . . . . 123

\section{Reseñas}

Gilberto Giménez. Estudios sobre la cultura y las identidades sociales. México: Conaculta/ITESO, 2007

Ana Lourdes Álvarez Romero . . . . . . . . . . . . . . . . . . . 135

Angélica Tornero. El mal en la narrativa de Inés Arredondo. México: Casa Juan Pablos/Universidad Autónoma del Estado de Morelos, 2008

Griselda Córdova Romero . . . . . . . . . . . . . . . . . . . . . . . 141

Guadalupe Fernández Ariza, coord. Literatura hispanoamericana del siglo XX. Historia y maravilla. España: Universidad de Málaga, 2006

Mayra Alejandra Borbón Espinoza . . . . . . . . . . . . . . 147

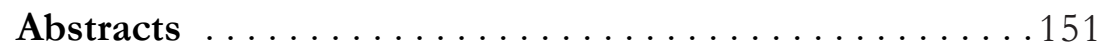

Résumés ... . . . . . . . . . . . . . . . . . . . . 157

Normas editoriales ..................... 163 


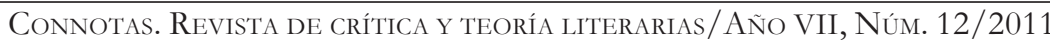

\title{
Metaficción hispanoamericana y crisis de la representación literaria del sujeto
}

\author{
Jesús Eduardo Oliva Abarca*
}

\section{Resumen:}

La categoría del sujeto se representa, usualmente, a través de tres instancias esenciales al texto literario: la instancia autoral, la instancia narrativa y la de los personajes. La metaficción es un modo de escritura a la vez creativa y crítica, que evidencia los problemas relativos a los modos de representación de una consciencia subjetiva a través del lenguaje literario. Mi objetivo en este trabajo es analizar las estrategias a través de las cuales la metaficción problematiza la noción de sujeto en cada una de las tres instancias mencionadas antes. Para tal fin, examino Abbadón el exterminador, de Ernesto Sabato, Boquitas pintadas, de Manuel Puig, y Farabenf, de Salvador Elizondo.

Palabras clave:

Modernidad, posmodernidad, Manuel Puig, Ernesto Sabato, Salvador Elizondo, narrativa.

\section{Entre modernidad y posmodernidad}

Uno de los debates actuales más recurrentes en el campo de los estudios humanísticos es el relativo a la llamada "crisis del sujeto," problemática que, desde diversos enfoques, se vincula a las contradicciones y estragos que continúa causando el tan anunciado cierre

\footnotetext{
${ }^{*}$ Centro de Investigaciones en Ciencias, Artes y Humanidades de Monterrey.
} 
de la modernidad y la anhelada -y temida- llegada de la posmodernidad. Sin duda, la época moderna ha estado fundamentada sobre la idea del autoconocimiento, de la autognosis. El ser humano comienza, durante este periodo, a tomar consciencia de sus propios alcances y capacidades, de su condición existencial y su esencia como ser racional diferente y específico. Aunque la autognosis viniera anunciándose desde la antigüedad, en los tiempos de los presocráticos, y del mismo Sócrates, era más un imperativo moral que una certeza ontológica. El "conócete a ti mismo" era una manera de adherencia a la vida pública, una participación en la polis, mientras que el cogito, ergo sum cartesiano, ya de significación metafísica, lleva en sí el germen de la revolución industrial y de las garantías individuales del hombre, es decir, anticipaba los altos vuelos del hombre moderno, para el que su "propio ser es invulnerable e invencible" (Cassirer 15).

Es la modernidad la época que inaugura la noción de sujeto. Si bien la época clásica sugería el nacimiento de tal concepto, no logra concretarse, pues el pensamiento griego prefería la impersonalidad del logos a la subjetividad del individuo, por ser éste esencialmente pathos, desenfreno, si no se encuentra regido por la racionalidad de la polis, por el ethos de la vida pública. La Edad Media tampoco conocía la noción de sujeto, por lo menos no la que la modernidad postula. Durante el Medioevo impera el pensamiento teológico, que concibe al hombre como la manifestación corpórea e imperfecta de la voluntad divina; el ser humano no es autónomo, mucho menos es su propia finalidad, y la subjetividad, atributo esencial de la noción moderna de sujeto, existe únicamente en virtud del pensamiento divino.

Es necesario indicar que el concepto de sujeto obedece a una doble necesidad histórica: por una parte, es una necesidad relacional, pues debe sacar a relucir la intrínseca naturaleza de la organización de la realidad, y ésta se constituye por medio de la relación bivalente entre sujeto y objeto; por otra parte, esta relación es esencialmente gnoseológica, es decir, el sujeto es siempre sujeto cognoscente y el objeto es siempre conocido. 
Aunque es difícil definir un exacto corte temporal para indicar el nacimiento de la modernidad, la mayoría de los teóricos coinciden en que ésta surge tras la sustitución del campo por la urbe como terreno privilegiado de producción y por el paso de una sociedad esencialmente agrícola a una industrial. Marx indica que una sociedad nueva, al ser el resultado de un cambio histórico, implica nuevas relaciones del hombre con su entorno, pues el curso de la historia, parafraseando al filósofo, no es sino una transformación continua de la naturaleza humana; de ello se sigue que la modernidad estableciera nuevas relaciones respecto a los modos en que el ser humano concibe su mundo y a sí mismo. Así pues, la modernidad marca el cambio para que el concepto de sujeto satisfaga la doble necesidad histórica indicada antes, pues el cambio de las relaciones productivas del hombre con su entorno es también un cambio en sus relaciones epistemológicas con el mundo.

La idea de sujeto comienza a delinearse muy tímidamente en René Descartes. El “yo pienso," axioma de la filosofía moderna, es el hallazgo de una subjetividad que se percibe a sí misma como pensante. Aunque por razones políticas Descartes no desarrolla las consecuencias de su propia metafísica de la res cogitans, el paradigma y la filosofía ya habían cambiado, y con ello la especulación científica moderna remplaza su objeto de estudio, que era el universo -la unidad de todo lo existente-, por el mismo ser pensante que se interroga sobre lo cognoscible. Kant continúa por el camino trazado por Descartes, pero se deslinda del idealismo problemático de este último y, en cambio, interroga al yo pensante de Descartes acerca de la certeza de sus propias percepciones y conceptos. Éste es el sentido del criticismo kantiano: en él, la noción del yo, que es semejante al concepto foucaultiano de sujeto, no es la de un yo sustancial, cartesiano; al contrario, el yo kantiano no es incondicional ni existe por sí mismo, sino que se unifica en el análisis y síntesis de los fenómenos; existe en relación con las apariencias y su autoconocimiento sólo es posible por la mediación del no-yo, es decir, del objeto. Se puede inferir que, aunque invento moderno, el concepto de sujeto, en sus primeros esbozos, era ya de por sí problemático. 
Sin embargo, en el idealismo alemán posterior a Kant, la idea de sujeto adquiere la formulación actual y, sobre todo, su autojustificación. Los trabajos de Fichte y Hegel nos remiten a los atributos que actualmente seguimos postulando acerca del sujeto: razón autónoma, autotélico, reflexivo. El sujeto de Fichte, y sobre todo el de Hegel, abandona la incertidumbre kantiana acerca de su propia actividad cognoscente al reconocer que él es a la vez sujeto cognoscente y objeto conocido; el idealismo alemán suprime, pues, la dicotomía gnoseológica del sujeto-objeto al hacer del primero el contenido y fin de su propia actividad reflexiva. Es la autoconciencia, o la conciencia que retorna a sí misma, el principal atributo que posee el sujeto, epítome de una modernidad optimista de sus propios alcances.

Pero el descubrimiento del sujeto, aunque relativamente reciente, está siendo superado en lo que los actuales estudios culturales denominan posmodernidad. Se define a la posmodernidad por la transición de la sociedad industrial a la postindustrial y por el cambio paradigmático que va de la cultura de la imprenta a la informática; igualmente este concepto se concibe como la superación consciente, radical y abiertamente agresiva de la modernidad. Aunque esta visión no es del todo equivocada, no deja de resultar parcial. Una perspectiva más equilibrada, a mi parecer, es la que elabora Linda Hutcheon. Según esta autora, la posmodernidad no es la antítesis de la modernidad, pero tampoco es su continuación. La teórica postula que este fenómeno es una reflexión consciente sobre los aparatos institucionales y los conceptos centrales sobre los que la modernidad asentaba sus bases más sólidas; dicha reflexión conlleva necesariamente una postura crítica, pero no esencialmente nihilista, sino constructiva:

Postmodernism challenges some aspects of modernist dogma: its view of the autonomy of art and its deliberate separation from life; its expression of individual subjectivity; its adversarial status vis-à-vis mass culture and bourgeois life [...]. But, on the other hand, the postmodern clearly also developed out of other modernist strategies: its self-reflexive 
experimentation, its ironic ambiguities, and its contestations of classic realist representation. ${ }^{1}$ (A Poetics 45)

A diferencia de los detractores de la posmodernidad, que ven ésta como un fenómeno negativo y anárquico, Hutcheon continúa la línea sugerida por Habermas y Foucault y analiza las relaciones existentes entre sujeto, discurso, poder e historia. Para Hutcheon, el sujeto sustancial, autoconsistente, de la modernidad, se disuelve en su propia expresión, en el discurso que valida su subjetividad. Toda experiencia, al ser mediada por el lenguaje, se convierte ella misma en texto, pues la subjetividad es fundamentalmente lenguaje (168). Incluso la historia, largamente considerada como fidedigna representación de la realidad pretérita, bajo la perspectiva posmodernista se relativiza, se volatiliza en la disparidad de los textos -testigos, testimonios, documentos- que la sustentan, pues estos son objeto de interpretación; están sometidos, pues, a la subjetividad del intérprete. El sujeto es, desde la perspectiva posmoderna, una entidad constituida por el lenguaje institucionalizado, el de la historia, la literatura, los medios, la moral, etc.; el sujeto no es entonces una entidad soberanamente libre e independiente, dueño incuestionable de sí mismo: "If the speaking subject is constituted in and by language, she cannot be totally autonomous and in control of her or his own subjectivity, for discourse is constrained by the rules of the language and open to multiple connotations of anonymous cultural codes" (Hutcheon, $A$ Poetics 168). ${ }^{2}$

${ }^{1}$ El posmodernismo se opone a algunos aspectos del dogma modernista, como a la visión de la autonomía del arte y su separación de la vida, o la expresión de la subjetividad individualista, su postura de separación entre cultura de masas y burguesía... Por otra parte, el posmodernismo desarrolla también muchas de las estrategias modernistas, tales como la experimentación autoreflexiva, la ironía ambigua y la contestación a la representación clásica realista] (En este caso, como en los que continúan, la traducción es mía).

${ }^{2}$ [Si el sujeto hablante se constituye en y por el lenguaje, el/ella no puede dominar por complete su propia subjetividad, pues el discurso está constreñido a reglas del lenguaje y abierto a múltiples connotaciones de códigos culturales anónimos.] 
Creo adecuado, entonces, sugerir que si la modernidad descubrió y dio forma a la noción de sujeto, la posmodernidad señala que éste no es absoluto, que la experiencia subjetiva no es nunca totalizadora, ilimitada y absoluta, sino más bien parcial, limitada y relativa. La postura posmodernista afirma que todo es relativo, e inmediatamente señala -irónica y divertida- la paradójica relatividad de esa misma frase. La modernidad se maravillaba del poder de la subjetividad autoconsciente; la posmodernidad, en cambio, indica las limitaciones de esa misma autoconsciencia: no es una negación de la subjetividad, sino la interrogación acerca de si realmente el sujeto es una unidad, fenomenológica y psicológicamente hablando.

La discusión sobre el concepto de sujeto se ha trasladado del campo de la reflexión cultural y filosófica al terreno del arte, en específico, al de la literatura. Una práctica narrativa actual es la metaficción, escritura autorreferencial y autointerrogativa que traduce al lenguaje literario los problemas más relevantes de las diferentes ciencias humanas. Es pertinente anotar, junto a Hutcheon, McHale y Waugh, entre otros, que el tema y problemática del sujeto es de importancia capital en la metaficción, producto artístico, a decir de estos autores, que expresa con fidelidad las antinomias entre modernidad y posmodernidad.

\section{Metaficción y crisis representativa}

Patricia Waugh define la metaficción como una escritura ficcional que "self-consciously and systematically draws attention to its status as an artifact in order to pose questions about the relationship between fiction and realit" (2). ${ }^{3}$ El término fue acuñado originalmente por William H. Gass en su ensayo Fiction and the Figures of Life, y estaba ligado con una práctica de escritura trasgresora, iróni-

${ }^{3}$ [una escritura ficcional que autoconsciente y sistemáticamente atrae la atención a su estatus como un artificio para interrogarse acerca de la relación entre ficción y realidad]. 
ca y, sobre todo, autoconsciente de su condición de mensaje literario. El término fue rápidamente adoptado por la teoría literaria anglosajona, constituyendo un amplio campo de estudio y, además, de especulación sobre la condición actual de la novela y su porvenir. Así pues, los detractores de lo que el término designa afirman que la metaficción no es más que el signo de un género cansado y caduco, que se ataca a sí mismo, ya consciente de que sus alcances son nulos y que su muerte está cerca; mientras tanto, los apologistas de esta nueva forma de expresión literaria ven en ésta la renovación, divertida y juvenil, de un género que, lejos de estar moribundo, bromea con su tan anunciada defunción.

Independientemente del destino de la novela, algunos teóricos han emprendido la tarea de elaborar una poética de este fenómeno novelístico. Los esfuerzos más acabados pertenecen a Linda Hutcheon y Patricia Waugh, quienes, respectivamente, esbozan tipologías que intentan comprender las formas y variantes de la metaficción. La importancia de tal empresa, como intentan demostrar estas autoras, radica en el hecho de que la relación que las formas novelísticas guardan con la realidad es aún más compleja de lo que se pudiera creer. Ambas autoras coinciden en definir la metaficción como una manera de escritura que, al exponer su propia condición de artificio, revelando las técnicas por las cuales se constituye, plantea la interrogante de la distinción entre lo real y lo ficticio.

A este respecto, el planteamiento hecho por Hutcheon es, a mi parecer, bastante valioso, pues sitúa el problema en el terreno de la mímesis. La metaficción continúa siendo ficción; únicamente ha variado el objeto en el que el acento de la escritura recae. La naturaleza de la mímesis en la literatura es problemática, pues, como indica Genette, existen diversos tipos de representación que poseen desigual estatus literario (201). Así pues, la descripción, que es la representación de la existencia espacial de objetos, es en cierta medida una mímesis más pura, mientras que la narración, que incluye la dimensión temporal en la existencia de los objetos, es una mímesis imperfecta. Genette resuelve el problema de la representación confrontando los conceptos de mímesis y diégesis en los antiguos, y afirma que la distinción entre imitación perfecta e imper- 
fecta no puede sostenerse pues "la imitación perfecta ya no es una imitación, es la cosa misma y finalmente la única imitación es la imperfecta. Mímesis es diégesis" (200). Por lo tanto, la esencia de la mímesis literaria consiste en la representación discursiva, verbal, de la existencia espaciotemporal de seres y cosas, es decir, en el relato.

El mismo Genette, sin embargo, observando la recurrencia de una literatura autorreferencial, intuye el problema que la representación significaría para este tipo de escritura: "Todo sucede aquí como si la literatura hubiera agotado o desbordado los recursos de su modo representativo y quisiera replegarse sobre el murmullo indefinido de su propio discurso. Quizá la novela, después de la poesía, vaya a salir definitivamente de la edad de la representación" (209). Si ajustamos estas palabras de Genette a la metaficción, podría concluirse que ésta es, esencialmente, un hecho lingüístico, un retorno de la novela a su misma constitución verbal. De ello hay ejemplos en la novela hispanoamericana moderna; baste Tres tristes tigres, de Guillermo Cabrera Infante, novela esencialmente sonora en que confluyen los distintos "dialectos" de los habitantes nocturnos de la Habana. Los personajes son voces; existen como discursos en esa Habana ficticia de Cabrera Infante. Lo que con más fuerza resalta de la novela es su oralidad; la mímesis aquí no es representación de la realidad, sino del discurso con que se le construye u ordena. La novela, pues, no abandona la edad de la representación, solamente la modifica.

Hutcheon está consciente de este cambio de paradigma y afirma que "Metafiction is still fiction, despite the shift in focus of narration from the product it presents to the process it is. Autorepresentation is still representation" (Narcissistic 39). ${ }^{4}$ La metaficción no anula la representación al recluirse dentro de su propio material verbal, al contrario, hace de la representación una experiencia reflexiva, es decir, autoconsciente. La autora define esta transición por la distin-

${ }^{4}$ [La metaficción es aún ficción, a pesar de que la narración se enfoque, no ya en el producto presentado, sino en el proceso por el que se lleva a cabo. La autorrepresentación continúa siendo representación] 
ción entre mímesis del producto y mímesis del proceso. La primera, característica del realismo literario según la autora, consiste en considerar la obra como una representación verosímil de la realidad representada; de este modo, el mundo ficticio de la novela es una suerte de continuación del mundo social, moral, etc., externo. La mímesis del proceso, que para la autora es el paradigma de la metaficción, consiste en incorporar a la ficción el problema de la génesis, la escritura, la creación y la recepción de la obra. El universo ficticio no guarda con la realidad una relación de continuidad, sino de diferenciación. Tanto para Hutcheon como para Patricia Waugh, esta diferenciación cumple una función creativa y crítica a la vez: la ilusión de la ficción, al evidenciarse como tal, es una crítica consciente a las instituciones y convenciones culturales, así como a las maneras en que el sujeto humano construye, por medio del lenguaje, su realidad.

Éste es, quizá, uno de los puntos más importantes del estudio de la metaficción: la representación, ahora autorrepresentación, señala hacia la noción filosófica de sujeto, pues es éste un tema que, aunque presente implícitamente en la literatura, cobra una relevancia capital en este modo contemporáneo de escritura. A este respecto, me parece adecuado investigar cuáles serían los modos discursivos más generales de que se sirve la metaficción para exponer las dificultades de la representación del sujeto.

\section{El problema del sujeto en la metaficción}

Creo que un acercamiento pertinente al problema de la representación del sujeto en la metaficción se daría primeramente estableciendo las "instancias" en las que la noción es más fácilmente identificable. Considero que estas instancias corresponden a las categorías del autor, narrador y los personajes. A continuación analizaré la instancia que corresponde a la figura del autor, auxiliándome de la lectura de Abbadón el exterminador, de Ernesto Sabato, una novela decididamente metaficcional.

Esta novela de Sabato tiene un inicio muy interesante: 
EN LA TARDE DEL 5 DE ENERO, de pie en el umbral del café de Guido y Junín, Bruno vio venir a Sabato, y cuando se disponía a hablarle sintió que un hecho inexplicable se produciría: a pesar de mantener la mirada en su dirección, Sabato siguió de largo, como si no lo hubiese visto. Era la primera vez que ocurría algo así y, considerando el tipo de relación que los unía, debía excluir la idea de un acto deliberado, consecuencia de algún grave malentendido. (11)

Seguidamente, el editor aclara en una nota a pie de página que Bruno es un personaje de la novela Sobre héroes y tumbas, del mismo Sabato. Desde el punto de vista de la composición literaria, esta mención del autor (aunque ficticio) dentro de su propia obra es un recurso metaficcional; Waugh lo denomina intrusión explícita del autor,' y considera a ésta una manera de llamar la atención acerca de la calidad ficticia del universo literario en que el lector se adentra al iniciar la lectura de una novela.

Aunque el recurso de por sí es tan antiguo como la literatura misma, en la novela actual es cada vez más frecuente, convirtiéndose en un elemento tematizado de la obra. Hutcheon establece una tipología de las formas metaficcionales, y las clasifica en "descubiertas o encubiertas," dependiendo del grado de explicitación, a nivel diegético o lingüístico, que la obra despliegue. Esta intrusión del autor corresponde, en el nivel lingüístico, a una forma descubierta del narcisismo metaficcional, pues la intrusión de Sabato en su novela Abbadón imprime a la obra un pretendido sentido autobiográfico, que de inmediato anula la idea preconcebida de la narración como producto acabado. Sabato es un personaje más de su novela, coexiste junto con personajes de su imaginación y con personas de su vida real. Incluso en la novela son incorporados datos verídicos acerca de la trayectoria literaria y vital de Sabato: “-Casi al mismo tiempo que me metí en la física me metí en el marxismo. Y así pude vivir las dos experiencias más trastornadoras de nuestra época. En 1951 publiqué lo que podría llamar el balance de esas dos experiencias: Hombres y engranajes. Casi me crucifican" 
(195). El dato de publicación es correcto, al igual que la experiencia biográfica de Sabato, que abandona la ciencia por la literatura; sin embargo, en el contexto de la enunciación en que esta información nos es dada, el diálogo que Sabato comparte con Silvia pudo o no haber ocurrido, es decir, al ser un texto literario, ese diálogo queda en la incertidumbre entre lo real y lo ficticio.

Contrario a lo que inmediatamente pudiera pensarse, la presencia explícita de Sabato en la novela no es una afirmación del sujetoautor, sino la revelación de su fragilidad. Sabato, el escritor, el hombre social, al desdoblarse en el Sabato de Abbadón, plantea la cuestión que ya Foucault, en su ensayo "¿Qué es un autor?," estableciera como principio ético de la escritura contemporánea: ¿qué importa quién habla?, en obvia alusión al trabajo literario de Samuel Beckett. Abbadón postula el problema del autor en relación con su obra. La preocupación de Sabato - del Sabato real y del ficticio- pudiera traducirse en la interrogante acerca de su propia identidad. La función-autor, siguiendo a Foucault, es una manera de autentificación del discurso, lo que nos hace ser propietarios de tal o cual texto al convertirlo en obra. Pero la noción de obra es problemática, pues de entre "los millones de huellas que alguien deja después de su muerte, ¿cómo puede definirse una obra?” (357). La presencia de Sabato en la novela es un modo por el cual anula la noción absoluta del autor de la obra, pues busca

Una novela en que esté en juego el propio novelista... no hablo de un escritor dentro de la ficción. Hablo de la posibilidad extrema que sea el escritor de la novela el que esté dentro. Pero no como un observador, como un cronista, como un testigo.

-¿Cómo entonces?

-Como un personaje más, en la misma calidad que los otros, que sin embargo salen de su propia alma. Como un sujeto enloquecido que conviviera con sus propios desdoblamientos. (248-249) 
Abbadón es una novela experimental. El escritor busca una escritura siempre actual, de ello que intente formar parte del universo que imagina, sometiendo la función-autor a la relatividad del discurso ficcional. A final de cuentas, el sujeto no puede ser representado de manera estable a través de la figura del autor, pues su discurso no es un objeto acabado ni permanente, sino un proceso, una escritura siempre en proyecto; no importa el autor, pues en la novela "-Estamos hablando de ficción, de poesía, hombre - dijo Sabato, ya con fastidio" (175).

Farabeuf, de Salvador Elizondo, es sin duda una obra compleja, cuya aparente fragmentariedad inclinaría a afirmar que no existe uno sino múltiples narradores cuyos discursos se contraponen e incluso se contradicen unos respecto a los otros. En esta novela la noción de sujeto es criticada de una manera aún más radical que en la de Sabato. De acuerdo al "espectro metaficcional" que propone Waugh, Farabeuf es una metaficción 'radical', pues pertenece a este tipo de novelas que, parafraseando a Waugh, operan a través de descontextualizaciones abruptas, no poseen un punto de vista estable o una perspectiva central cuyo narrador sea confiable y, sobre todo, confunden diferentes planos ontológicos, haciendo imposible la distinción entre "sueño", "alucinación", "ficción" o "realidad". En palabras sencillas, este tipo de obras metaficcionales dificultan al lector una interpretación totalizante de la obra, sugiriéndole - de maneras más o menos 'textualmente' violentas- que la "realidad" y la "ficción” no son otra cosa más que juegos lingüísticos (136-137). La manera en que Waugh caracteriza la actitud del lector frente a este tipo de metaficciones le viene muy bien a Farabeuf: de lo único que el lector puede estar seguro es de las tapas del libro.

Imposible resumir, por ejemplo, el argumento de la novela de Elizondo. Podemos, a lo mucho, sugerir que es la historia de la relación entre un hombre y una mujer que se encuentran en los límites de lo erótico y lo tortuoso, del encuentro sexual y del asesinato; historia que se nos va revelando, fragmentariamente, a través de recuerdos difusos y asociación de ideas, a la manera del "stream of consciousness" joyceano. Es importante señalar la modalidad de la voz narrativa, que se realiza completamente en segunda persona: el 
narrador, o mejor, los narradores (presumiblemente un hombre y una mujer) intentan comunicarse uno con otro a través de un diálogo imperfecto en el que no existe la posibilidad de réplica o contestación, pues emisor y destinatario se encuentran separados, sea por el tiempo o el espacio, o incluso por la vida o la muerte. Pudiera decirse que la novela se rige, a nivel fenomenológico, por tres "dominios" de percepción: el recuerdo, el reflejo y la experiencia límite de la tortura; pero, además, cada uno de estos dominios entra inmediatamente en oposición discursiva, produciendo una situación enunciativa, si bien seguramente ambigua, posiblemente dual. Un ejemplo, en el terreno del recuerdo, se da cuando un narrador apela a un narratario desconocido: "Tú recuerdas sus gestos llenos de fatiga, ¿no es así?... De seguro que has retenido todo esto en tu memoria" (14); páginas más adelante, podría suponerse que otro narrador contesta a esta primera pregunta: "No recuerdo nada. Es preciso que no me lo exijas. Me es imposible recordar" (23). Ya desde el principio, el lector no puede asumir la narración como la rememoración de un personaje ficticio, pues, dentro del mismo universo imaginario de la novela, la propia "autoridad autentificadora del discurso" (Martínez), que es el narrador, es contradicho por otro u otros narradores.

De manera parecida, el lector no puede recibir este texto como si se tratara de una ensoñación vista a través de un reflejo especular, ya que en el preciso momento en que se alude a esta posibilidad: "Hemos jugado a encontrar nuestras miradas sobre la superficie de aquel espejo" (49), es devastada de manera contundente: "¿Ve usted? La existencia de un espejo enorme, con marco dorado, suscita un equívoco esencial en nuestra relación de los hechos" (63). Si bien pudiera pensarse que la novela de Elizondo se trata de un texto críptico, que invita a que se descubra la clave de su funcionamiento -supuestamente la clave es leer el mensaje de frente al espejo-, la misma novela rechaza esta idea, pues los hechos -se sugiere- existen en su inmediatez, inasibles no sólo para el observador que busca insistente en el espejo, sino también para la memoria. En palabras de Hutcheon, ni psique ni interpretación permiten configurar un sujeto discursivo coherente, pues las relaciones 
de éste respecto a la historia, la sociedad, e incluso su subconsciente, son manifiestamente discontinuas (Narcissistic 166).

Cuando mencioné arriba la tortura como otro dominio de percepción, me refería a ésta como una dimensión de experiencia puramente corporal, mientras que el recuerdo es de índole cognitiva y el reflejo de naturaleza interpretativa. En el terreno de la tortura, experiencia límite y ambigua entre placer y dolor, la novela comienza a presentar cada vez mayores confusiones respecto a la identidad de los narradores: "Se trata de un hombre que ha sido emasculado previamente... Es una mujer. Eres tú. Tú. Ese rostro contiene todos los rostros" (146). En este punto, ni siquiera lo corporal ofrece garantía o certeza alguna del sujeto representado en un determinado discurso. No solamente la situación enunciativa es puesta en cuestión, también se interroga al género del sujeto que, muy vagamente, es representado en esta metaficción. ¿Quién habla? ¿Quien habla es un él o una ella? Éstas son preguntas a las que pudiera responder la siguiente observación de Hutcheon:

The metafictional self-consciousness about the hermeneutic power actually to constitute subjectivity finally points to the foregrounding of the text's 'cultural inscription' (Silverman 1983, 246), to its awareness that its discursive situation cannot ignore, by definition, the cultural and historical nature of its own utterance. And such an awareness cannot but involve, therefore, the issue of the gender of the subject constituted. $\left(A\right.$ Poetics 172) ${ }^{5}$

La última instancia de la que nos ocupamos sería la del personaje. Aunque ésta es una categoría sumamente problemática para la

${ }^{5}$ [La autoconciencia metaficcional finalmente descubre que la capacidad de constituir la subjetividad yace en las 'inscripciones culturales' del texto (Silverman 1983, 246), en el conocimiento de que no se puede ignorar la situación discursiva, es decir, la naturaleza histórica y cultural de su propia expresión. Y tal consciencia no puede sino incluir, el tema del género del sujeto constituido] 
teoría literaria, que continúa debatiéndose entre el funcionalismo (el personaje es una función narratológica) y el esencialismo (el personaje como ente significativo), me parece que es imprescindible al abordar el tema de la representación del sujeto discursivo. Existen incontables novelas hispanoamericanas que servirían para ilustrar esta problemática; sin embargo, me inclino por Boquitas pintadas, de Manuel Puig, pues es una obra que al explotar las formas discursivas y los géneros literarios populares (cartas, recortes periodísticos, novela rosa) trasgrede la noción tradicional de personaje sustancial.

La novela consta de dieciséis "entregas," desarrolladas a través de cartas, notas periodísticas y diálogos telefónicos. Se oscila entre la novela de folletín, la novela rosa o sentimental e, incluso, posee elementos que la equipararían con la novela negra. La historia se centra en Juan Carlos Etchepare, o mejor, en la historia detrás de la nota de su defunción con la que la novela comienza:

FALLECIMIENTO LAMENTADO. La desaparición del señor Juan Carlos Etchepare, acaecida el 18 de abril último, a la temprana edad de veintinueve años, tras soportar las alternativas de una larga enfermedad, ha producido en esta población, de la que el extinto era querido hijo, general sentimiento de apesadumbrada sorpresa, no obstante conocer muchos allegados la seria afección que padecía. (9)

La muerte de este personaje suscita una serie de narraciones, todas ellas objeto de las "entregas." Los allegados de Juan Carlos -familiares, amigos, amantes y novias- van relatando la historia personal de éste, de manera un tanto fragmentaria, sin la necesaria linealidad cronológica de una biografía bien constituida, antes bien, de acuerdo a sus propias apreciaciones sobre el fallecido. A través del intercambio epistolar entre los distintos personajes, se va perfilando, si bien parcialmente, la personalidad de Juan Carlos; pero este sujeto no es otra cosa que una construcción verbal, producto de la alternación entre diversas subjetividades que se esfuerzan por unificar todos los discursos que sobre el fallecido orbitan en una 
única y consistente historia personal; en otras palabras, los demás personajes hacen un esfuerzo por reconstruir narrativamente la figura de Juan Carlos Etchepare.

La novela, además, recurre abiertamente a trasgresiones transtextuales, es decir, se sirve de textos de distinta naturaleza a la literaria, como la incorporación de fragmentos de boleros o tangos al principio de cada "entrega", el mismo recurso de la redacción de estilo periodística o, en el caso de la "sexta entrega", el desarrollo de las "romerías populares", que sirve de pretexto para exponer con mayor detalle a la "Raba". Este procedimiento de 'mixtura' textual es, según Patricia Waugh, una estrategia común de la metaficción, consistente en la "sobrecarga intertextual" ("intertextual overkill"), que, en el caso específico de Boquitas pintadas, tiene por resultante fragmentar aún más al personaje protagónico, del que únicamente sabemos con certeza sus nombres de pila y su apellido.

La reconstrucción textual que sobre Juan Carlos intentan los otros personajes se revela, sin embargo, imperfecta, discontinua, por las mismas inconsistencias y contradicciones del finado que, estando al tanto de su tuberculosis, continúa manteniendo distintos romances. Hay, en este sujeto discursivo reconstruido, una cierta ambigüedad, producto de su misma naturaleza conjetural, como lo evidencian las "interrogantes del ocupante de la habitación catorce:"

¿tenía conciencia Juan Carlos de la gravedad de su mal? ¿aceptaría Nené, en caso de ser virgen, casarse con un tuberculoso?

¿aceptaría Nené, en caso de no ser virgen, casarse con un tuberculoso? (117)

Hay que insistir en que el personaje Juan Carlos es un ente de naturaleza verbal, no solamente por el hecho de ser un constructo ficcional, sino además porque, como nos revela la sucesión de "entregas," Juan Carlos Etchepare consiste en las diversas -y hasta opuestas- versiones de Nené, Mabel, la "Raba," etc. El Juan Carlos del que estas mujeres hablan es un producto de sus respectivos discursos sobre un antiguo novio. Desde el punto de vista del lec- 
tor, el sujeto protagónico de la novela nunca nos es presentado de manera clara; de éste sólo conocemos algunos trazos personales, fragmentos narrativos esbozados por sus allegados y por él mismo. El final de la novela pareciera apoyar esta idea:

...mirá, rubia, ya de charlar un poco con vos me siento mejor ¡cómo será cuando te vea..." “...te quiero como no he querido a nadie..." "...También hay un hospital en Cosquín..." “...ni bien tenga más noticias te vuelvo a escribir..." “...el agua del río es calentita..." “...vos también estás lejos..."

"...pero cada vez que leo tu carta me vuelve la confianza..." (258)

Recapitulando, y a modo de conclusión, se puede decir que la metaficción hispanoamericana asume la problemática del sujeto haciendo evidente la actual crisis de los modos literarios de representación. A mi parecer, este proceso consiste en una renovación de la novelística, que se esfuerza, con particular vitalidad, en impedir el anquilosamiento de las convenciones autorales, narrativas o de los personajes y, sobre todo, que se postula en contra de toda certeza cómoda.

\section{Bibliografía}

Cassirer, Ernst. Antropología filosófica. Introducción a una filosofía de la cultura. Tr. Eugenio Ímaz. México: FCE, 1965.

Elizondo, Salvador. Farabeuf. México: Joaquín Mortiz/SEP, 1985.

Foucault, Michel. "¿Qué es un autor?” Textos de teorías y crítica literarias (del formalismo a los estudios poscoloniales). Comps. Nara Araujo y Teresa Delgado. México: Universidad Autónoma Metropolitana/Universidad de la Habana, 2003.

Genette, Gerard. "Fronteras del relato." Análisis estructural del relato. Eds. Roland Barthes, et al. Tr. Beatriz Dorriots. México: Premia, 1982. 
Hutcheon, Linda. A Poetics of Postmodernism. Histoy, Theory, Fiction. New York: Routledge, 1995.

. Narcissistic Narrative. The Metafictional Paradox. Ontario: Wilfrid Laurier University Press, 1980.

Martínez Bonati, Félix. La ficción narrativa: su lógica y ontología. Chile: Editorial Lom, 2001.

Sabato, Ernesto. Abbadón el exterminador. México: Seix Barral/ Artemisa, 1985.

Puig, Manuel. Boquitas pintadas. México: Planeta, 2000.

Waugh, Patricia. Metafiction. Theory and Practice of Self-Conscious Fiction. New York: Routledge, 1988. 